\begin{tabular}{lc}
\hline CURRENT & ISSN: 0973-4929, Vol. 16, No. (2) 2021, Pg. 436-443 \\
WORLD & Current World Environment
\end{tabular}

ENYIRONMENT

www.cwejournal.org

\title{
Adsorptive Studies for the Removal of Crystal Violet Dye from Aqueous Solution by using Cicca acida $\mathrm{L}$. Stem - Activated Carbon
}

\author{
SHARMILA RAMASAMY ${ }^{1}$, ANBARASU KALIYAPERUMAL ${ }^{1 *}$ \\ and THAMILARASU POMMANAICKAR ${ }^{2}$
}
${ }^{1}$ Department of Chemistry, Arignar Anna Government Arts College, Musiri, Affiliated to Bharathidasan University, Tiruchirappalli - 620 024, Tamilnadu, India.
${ }^{2}$ Department of Chemistry, Arignar Anna Government Arts College,
Namakkal - 637 002, Tamilnadu, India.

\begin{abstract}
Textile industries discharge wastewater containing various dyes including Crystal Violet dye. These dyes are very harmful for human beings, animals and plants. Therefore, the attempt is made for adsorption framework on elimination of crystal violet dye by using Cicca acida $L$. stem-activated carbon from aqueous solution carried out under various experimental methods and optimization conditions. Adsorption data modeled with Freundlich, Langmuir and Tempkin adsorption isotherms. Thermodynamic factors like as $\Delta \mathrm{H}^{\circ}, \Delta \mathrm{S}^{\circ}$ and $\Delta \mathrm{G}^{\circ}$ were calculated, which indicated that the adsorption was spontaneous and endothermic nature. Based on kinetic study, pseudo-second order kinetic model was fit compared to the pseudo-first order kinetic model. The adsorbent has been characterized by SEM before and after adsorption of crystal violet dye solution.
\end{abstract}

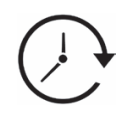

\section{Article History}

Received: 03 May 2021

Accepted: 24 May 2021

\author{
Keywords \\ Adsorption; \\ Isotherm; \\ Kinetic; \\ Crystal Violet Dye; \\ SEM.
}

\section{Introduction}

Various developed productions comparable dyes, plastics, textiles and paper productions using dyes in direction to colour produces too ingest considerable progression of water. As a consequence it types a significant quantity of coloured wastewater. It devises improved concerning the long period of poisonous outcome of water covering these liquefied contaminants. Dyes holding wastewater is frequently unconfined straight into the adjoining stagnant ponds, drains and river. Such wastewater discarding to environment, to polluting water bodies, the water eco-system and biodiversity of water atmosphere. ${ }^{1}$

Existence of lesser quantity of colorants (less than $1 \mathrm{ppm}$ ) is extremely noticeable; objectionable

CONTACT Anbarasu Kaliyaperumal $\$ arasu007@gmail.com Department of Chemistry, Arignar Anna Government Arts College, Musiri, Affiliated to Bharathidasan University, Tiruchirappalli - 620 024, Tamilnadu, India.

\section{(c) (P)}

(c) 2021 The Author(s). Published by Enviro Research Publishers.

This is an $\partial$ Open Access article licensed under a Creative Commons license: Attribution 4.0 International (CC-BY).

Doi: http://dx.doi.org/10.12944/CWE.16.2.10 
besides essentials to be separate earlier the wastewater can be liquidated into the atmosphere. ${ }^{2}$ It is challenging to confiscate the colorants from the industrialized waste, since colorants are not simply degradable. ${ }^{3}$ Exploration towards period includes several approaches to eliminate dyes remained systematically considered such as coagulation, adsorption, photo-oxidation, nano-filtration, ultrafiltration, flocculation, adsorption on triggered carbon, etc. But the system remains precise costly. Consequence, different environmental-friendly proficiency has developed an essential for the colour production. Amongst these systems, adsorption is a broadly used for colorant elimination from fabric wastewater ${ }^{4}$ Ground triggered carbon or pulverised triggered carbon is normally recycled for colorant deletion. ${ }^{5,6}$ Hence, the usage of some low price adsorbents devises has been considered as several studies. They must be considered as probability of consuming low price ingredients such as waste orange peel, ${ }^{7}$ lemon peel, ${ }^{8}$ banana pith, bentonite clay, powdered activated sludge, neem leaf powder, perlite; bamboo dust, duck weed, algae, straw, sewage sludge, etc.

Adsorbents are commonly recycled for its Environmental-friendly behaviour, availability in environment besides are very considerable charge effective. It can be remain recycled an effectual besides charge effective bio-adsorbent for removing colorants from industrialized effluents. ${ }^{9}$ In addition, unrefined sawdust is substitute an adsorbent for plenty environment, non-poisonousness and biodegradability. ${ }^{10}$ Mostly, maximum generally recycled adsorbent for colorant removal activated carbon, since of its high surface zone besides ability for proficiently adsorbing wide variety of different kind's adsorbates. ${ }^{11}$ However, usage remains partial as high price and renewal price stands equally very high. Hence, usage in behaviour of wastewater might remain sparingly not feasible. An essential to learning the adsorptive features of little cost adsorbents. ${ }^{12}$ Usage of non-conventional adsorbents, mainly stand for certainly renewed, change activated carbon in elimination of colorant from wastewater has mentioned.

Total adsorbent may subsidise near the sustainability of the atmosphere and offer encouraging profits for the feasible resolution in imminent. Plenty of besides little rate of agrarian derivatives and hopeless houseplant supplies marks them righteous precursor for grounding of activated carbon. Activated carbon previously equipped from agrarian surplus and spare houseplant supplies like peanut hull, ${ }^{13}$ rice husk, ${ }^{14}$ orange waste, ${ }^{15}$ cashew nutshells, ${ }^{16}$ tobacco stem ash, ${ }^{17}$ coffee husks, ${ }^{18}$ saw dust, ${ }^{19}$ palm kernel coat, ${ }^{20}$ eucalyptus bark, ${ }^{21}$ corncob, ${ }^{22}$ pine saw dust, ${ }^{23}$ modified mango seed, ${ }^{24}$ babool wood, ${ }^{25}$ etc. The rate of activated carbon armed from remaining provisions is insignificant related to the profitable activated carbon. Amongst several industries that donate colored effluent, textile, dye manufacturing, paper and pulp, tanneries are the most. ${ }^{26}$

Based on the above literature review, the carbonized Cicca acida $L$. stem activated carbon (CASAC) is cheap and low cost material obtained from the local area and used to study adsorption of Crystal Violet dye (CVD) from aqueous solutions.

\section{Materials and Methods Materials}

The Crystal Violet dye (E-Merck) aqueous solution was used as adsorbate and Cicca acida L. stem activated carbon was used as adsorbent. Entirely, the chemicals were recycled for these revisions are commercially obtainable Anala $\mathrm{R}$ grade (E-Merck and SD-fine, India).

\section{Methods}

Activated carbon was prepared from Cicca acida $L$. stem activated carbon and this uncooked solid was acquired from a resident vendor. The solid material was washed with hot distilled water to eliminate the earthy matter, cut into lesser sizes and dehydrated up. The activated carbon was organized the exceeding materials soaked through Concentrated $\mathrm{H}_{2} \mathrm{SO}_{4}$. For soaked, a share of $0.5: 1$ of acid volume and weight of the material occupied. Afterward, the burnt solid material cleaned some times in distilled $\mathrm{H}_{2} \mathrm{O}$ until, $\mathrm{pH}$ of washing befits impartial. Then solid material was dehydrated and carbonized at $350^{\circ} \mathrm{C}$ expending muffle furnace (Techno). Lastly, it ground and sieved the activated carbon used for further studies.

A standard aqueous solution of the adsorbate comprising $1000 \mathrm{mg} / \mathrm{L}$ of dye solution arranged through dissolving well-known quantity of Crystal Violet Dye (CVD) in twice purified $\mathrm{H}_{2} \mathrm{O}$. Doubly purified liquid was recycled during the experimentations. The 
adsorption experimentations remained accepted in consignment symmetry process. $100 \mathrm{mg}$ of adsorbent taken in the iodine flask and added 100 $\mathrm{ml}$ of known concentration of CVD solution and mixture was agitated with different time intervals in hotness regulator water-bath shaker (Techno). The solutions centrifuged at systematic intermissions besides remaining concentration of CVD solution existing in filtrate at every time was determined by using Spectrophotometer (Systronics 169 model) at $592 \mathrm{~nm}$. The experiments were continual by three dissimilar temperatures viz., 303, 313 and 323K for confiscation of CVD solution. The adsorption study was characterized by using Fourier Transform Infrared Spectroscopic (FTIR) and Scanning Electron Microscopic (SEM) Study.

\section{Results and Discussion}

Effect of Adsorbent Dosage, pH and Agitation Time

These experiments remained completed by expending from $50 \mathrm{mg}$ to $200 \mathrm{mg}$ of adsorbent, $100 \mathrm{ml}$ of $20 \mathrm{mg} / \mathrm{L}$ of CVD solution and agitation of various time intervals. Results indicated the optimum dosage was static as $100 \mathrm{mg}$ owed to the measure of dye uptake was high; the optimal $\mathrm{pH}$ was static as 8 owing towards extreme confiscation of CVD solution and $\mathrm{pHzpc}$ value is 5.74. All the experiments conducted at optimal agitation time of 50 min. ${ }^{27}$

Effect of Initial Concentration and Temperature Table 3.1 showing that, the quantity of CVD adsorbed (qe) rises with the removal percentage falls while increasing the initial concentration of CVD, because of relatively greater driving force for mass transfer. At greater concentrations of dye solution, dye removal decreased, due to reduced obtain ability of active sites on surface of CASAC as such as mass transfer resistances between aqueous solution and solid phase. ${ }^{28}$ The removal of CVD percentage increases from $30^{\circ} \mathrm{C}$ to $50^{\circ} \mathrm{C}$, the process of adsorption probably endothermic nature. These results showed that, avoidance tendency of CVD from solid phase to bulk phase, due to electrostatic interaction between active sites of adsorbent and adsorbate species.

Table 3.1: Equilibrium parameters and removal of CVD

\begin{tabular}{|c|c|c|c|c|c|c|c|c|c|}
\hline \multirow[t]{2}{*}{$\begin{array}{l}\text { Initial Conc. of } \\
\operatorname{CVD}\left(C_{0}\right), \mathrm{mg} / \mathrm{L}\end{array}$} & \multicolumn{3}{|c|}{$\begin{array}{l}\text { Equilibrium Conc. } \\
\text { of CVD }\left(C_{e}\right), m g / L\end{array}$} & \multicolumn{3}{|c|}{$\begin{array}{l}\text { CVD adsorbed quantity } \\
\text { at equilibrium }\left(q_{e}\right), \mathrm{mg} / \mathrm{g}\end{array}$} & \multicolumn{3}{|c|}{ Removal of CVD (\%) } \\
\hline & $30^{\circ} \mathrm{C}$ & $40^{\circ} \mathrm{C}$ & $50^{\circ} \mathrm{C}$ & $30^{\circ} \mathrm{C}$ & $40^{\circ} \mathrm{C}$ & $50^{\circ} \mathrm{C}$ & $30^{\circ} \mathrm{C}$ & $40^{\circ} \mathrm{C}$ & $50^{\circ} \mathrm{C}$ \\
\hline 20 & 4.136 & 2.500 & 1.046 & 15.86 & 17.50 & 18.95 & 79.32 & 87.50 & 94.77 \\
\hline 40 & 10.046 & 7.864 & 3.773 & 29.95 & 32.14 & 36.23 & 74.89 & 80.34 & 90.57 \\
\hline 60 & 18.318 & 15.636 & 9.227 & 41.68 & 44.36 & 50.77 & 69.47 & 73.94 & 84.62 \\
\hline 80 & 28.091 & 23.773 & 15.818 & 51.91 & 56.23 & 64.18 & 64.89 & 70.28 & 80.23 \\
\hline 100 & 39.364 & 36.136 & 27.546 & 60.64 & 63.86 & 72.45 & 60.64 & 63.86 & 72.45 \\
\hline
\end{tabular}

\section{Adsorption Isotherms}

The results of adsorption are generally defined and modelled based on adsorption isotherms. It refers to quantity of colorant adsorbed per unit weight of adsorbent to symmetry concentration of bulk phase. The linear form of Langmuir mode ${ }^{29}$ and Freundlich equation ${ }^{30}$ is used to study the adsorption isotherm.

The monolayer adsorption capacity $\left(Q_{0}\right)$ values decreases with temperature, signifying that adsorption is favoured at lower temperature. ${ }^{31}$ It can be recognized that dyes diffuse into adsorbent at slower rate with temperature increases. The energy of adsorption $\left(b_{L}\right)$ values suggests the affinities of binding sites with dyes are favourable. The values of adsorption capacity $\left(k_{f}\right)$ increased with temperature from $30^{\circ} \mathrm{C}$ to $50^{\circ} \mathrm{C}$. This shown adsorption is preferred at higher concentration. The adsorption intensity $(n)$ values slightly changes when temperature increases. The values of $n$ were found to be 2 . The values of all $n$ are $>1$, indicating favourable adsorption. Tempkin isotherm revealed the equilibrium binding constant readings and heat 
of adsorption readings are shown to lowest binding energy and lowest heat of adsorption by adsorption of CVD. The adsorption equilibrium data was presented in figure 3.1, figure 3.2. and table 3.2.

Table 3.2: Results for Adsorption Isotherm Models

\begin{tabular}{|c|c|c|c|c|c|c|c|c|c|}
\hline \multirow{3}{*}{$\begin{array}{l}\text { Temp. } \\
\left({ }^{\circ} \mathrm{C}\right)\end{array}$} & \multicolumn{3}{|c|}{ Langmuir Isotherm } & \multicolumn{3}{|c|}{ Freundlich Isotherm } & \multicolumn{3}{|c|}{ Tempkin Isotherm } \\
\hline & \multicolumn{3}{|c|}{$\begin{array}{l}\text { Correlation Constants } \\
\text { coefficient }\end{array}$} & \multicolumn{3}{|c|}{$\begin{array}{l}\text { Correlation } \\
\text { coefficient }\end{array}$} & \multicolumn{3}{|c|}{$\begin{array}{l}\text { Correlation Constants } \\
\text { coefficient }\end{array}$} \\
\hline & $r^{2}$ & $\begin{array}{c}Q_{o} \\
(\mathrm{mg} / \mathrm{g})\end{array}$ & $\begin{array}{c}\text { bL } \\
(\mathrm{L} / \mathrm{mg})\end{array}$ & $r^{2}$ & $k_{f}$ & $\mathbf{n}$ & $\mathbf{r}^{2}$ & $\begin{array}{c}\mathbf{b}_{\mathrm{T}} \\
\left(\mathrm{kJ} \mathrm{mol}^{-1}\right.\end{array}$ & $\begin{array}{c}a_{T} \\
(L / m g)\end{array}$ \\
\hline 30 & 0.998 & 90.909 & 0.049 & 0.995 & 7.161 & 1.684 & 0.995 & 13.865 & 45.462 \\
\hline 40 & 0.993 & 82.645 & 0.088 & 0.998 & 11.361 & 2.026 & 0.989 & 14.965 & 40.378 \\
\hline 50 & 0.997 & 84.034 & 0.212 & 0.994 & 19.611 & 2.404 & 0.995 & 16.353 & 38.289 \\
\hline
\end{tabular}

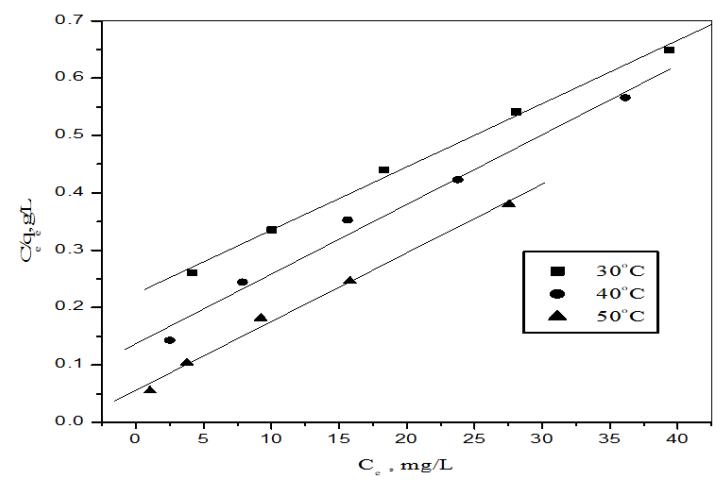

Fig. 3.1: Langmuir Adsorption Plot

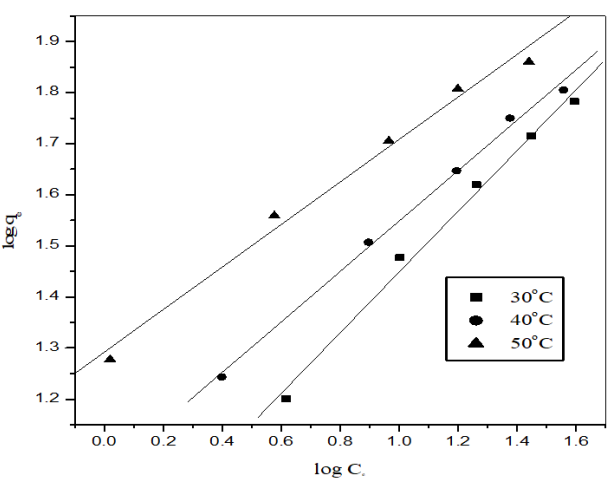

Fig. 3.2: Freundlich Adsorption Plot

Table 3.3: Thermodynamic Parameters

\begin{tabular}{|c|c|c|c|c|c|c|c|c|}
\hline \multirow{2}{*}{$\frac{C_{0}}{(m g / L)}$} & \multicolumn{3}{|c|}{$\mathrm{K}_{\mathrm{o}}$} & \multicolumn{3}{|c|}{$\Delta \mathbf{G}^{\circ}\left(\mathbf{k J ~ m o l} \mathbf{~}^{-1}\right)$} & \multirow{2}{*}{$\frac{\Delta \mathrm{H}^{\circ}}{\left(\mathrm{kJ} \mathrm{mol}^{-1}\right)}$} & \multirow{2}{*}{$\frac{\Delta S^{\circ}}{\left(\mathrm{J} \mathrm{K}^{-1} \mathrm{~mol}^{-1}\right.}$} \\
\hline & $30^{\circ} \mathrm{C}$ & $40^{\circ} \mathrm{C}$ & $50^{\circ} \mathrm{C}$ & $30^{\circ} \mathrm{C}$ & $40^{\circ} \mathrm{C}$ & $50^{\circ} \mathrm{C}$ & & \\
\hline 20 & 3.84 & 7.00 & 18.13 & -3.39 & -5.06 & -7.78 & 63.02 & 218.58 \\
\hline 40 & 2.98 & 4.09 & 9.60 & -2.75 & -3.66 & -6.07 & 47.32 & 164.53 \\
\hline 60 & 2.28 & 2.84 & 5.50 & -2.07 & -2.71 & -4.58 & 35.72 & 124.13 \\
\hline 80 & 1.85 & 2.37 & 4.06 & -1.55 & -2.24 & -3.76 & 31.87 & 109.83 \\
\hline 100 & 1.54 & 1.77 & 2.63 & -1.09 & -1.48 & -2.60 & 21.65 & 74.66 \\
\hline
\end{tabular}

\section{Thermodynamic Parameters}

The equilibrium constants, standard $\Delta \mathrm{G}, \Delta \mathrm{H}$ and $\Delta S$ changes were shown in table 3.3. Based on above parameters, the endothermic process of adsorption showed by rises in Ko with increasing temperature. The results showed the standard free energy values increase with increasing initial CVD concentration. The standard $\Delta \mathrm{G}$ values negative, adsorption process is spontaneous. The $\Delta \mathrm{H}$ change observed from 21.65 to $63.02 \mathrm{~kJ} \mathrm{~mol}^{-1}$ for adsorption of CVD on CASAC. The standard enthalpy values are positive, suggested adsorption method is endothermic nature. Standard entropy values for the adsorption method are positive which was the 
range from 74.66 to $218.58 \mathrm{JK}^{-1} \mathrm{~mol}^{-1}$ for adsorption of CVD. It suggested that high degree of randomness at solid-solution interface by adsorption of CVD on
CASAC. The activation energy of the adsorption of CVD on CASAC was found to be $9.2549 \mathrm{~kJ} / \mathrm{mol} / \mathrm{K}$.

Table 3.4: Pseudo-first and Pseudo-second order kinetic models

\begin{tabular}{|c|c|c|c|c|c|c|c|c|c|}
\hline \multirow[b]{2}{*}{$\begin{array}{l}C_{o} \\
\text { (mg/L) }\end{array}$} & \multirow[b]{2}{*}{$\begin{array}{l}q_{\mathrm{e}}(\exp ) \\
(\mathrm{mg} / \mathrm{g})\end{array}$} & \multicolumn{4}{|c|}{ Pseudo-first order kinetic model } & \multicolumn{4}{|c|}{ Pseudo-second order kinetic mode } \\
\hline & & $\begin{array}{l}q_{e}(\text { cal }) \\
(m g / g)\end{array}$ & $\begin{array}{c}k_{1} \\
\left(\min ^{-1}\right)\end{array}$ & $\mathbf{r}^{2}$ & $\mathbf{P}$ & $\begin{array}{l}q_{e}(\mathrm{cal}) \\
(\mathrm{mg} / \mathrm{g})\end{array}$ & $\begin{array}{c}\mathbf{k}^{2} \\
\left(\mathbf{g ~ m g}^{-1}\right. \\
\left.\mathrm{min}^{-1}\right)\end{array}$ & $\mathbf{r}^{2}$ & $\mathbf{P}$ \\
\hline 20 & 15.864 & 1.478 & 0.048 & 0.971 & 90.681 & 16.077 & 0.069 & 0.999 & 1.328 \\
\hline 40 & 29.955 & 5.329 & 0.071 & 0.987 & 82.207 & 30.487 & 0.029 & 0.999 & 1.749 \\
\hline 60 & 41.682 & 3.377 & 0.021 & 0.974 & 91.896 & 42.553 & 0.015 & 0.999 & 2.047 \\
\hline 80 & 51.909 & 7.490 & 0.049 & 0.897 & 85.571 & 53.191 & 0.012 & 0.999 & 2.411 \\
\hline 100 & 60.636 & 8.124 & 0.032 & 0.935 & 86.601 & 62.112 & 0.008 & 0.999 & 2.375 \\
\hline
\end{tabular}

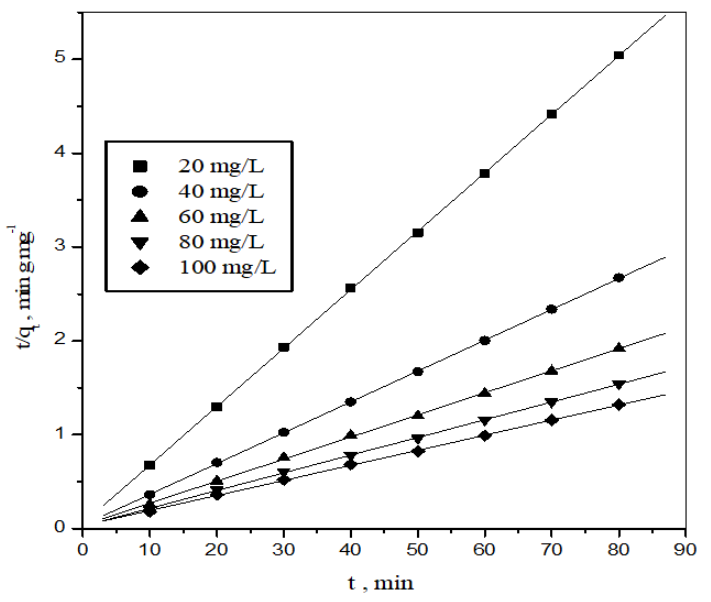

Fig. 3.3: Pseudo-second order kinetic plot

\section{Adsorption Kinetics}

To study Lagergren pseudo-first order and pseudosecond order adsorption kinetic models were used by adsorption data. The outcomes presented table 3.4 and figure 3.3. The correlation coefficient $\left(r^{2}\right)$ of kinetics of pseudo-second order found to be 0.999 . From the values of correlation coefficient and less percentage of deviation, this was showed that the pseudo-second order kinetic plot fit superior to the pseudo-first order kinetic plot.

\section{Scanning Electron Microscopic Studies}

The SEM photographs of CASAC before and after adsorption of CVD are showed in the figures 3.4 and 3.5. It was evidently stated that presence of porous structure of adsorbent before adsorption.

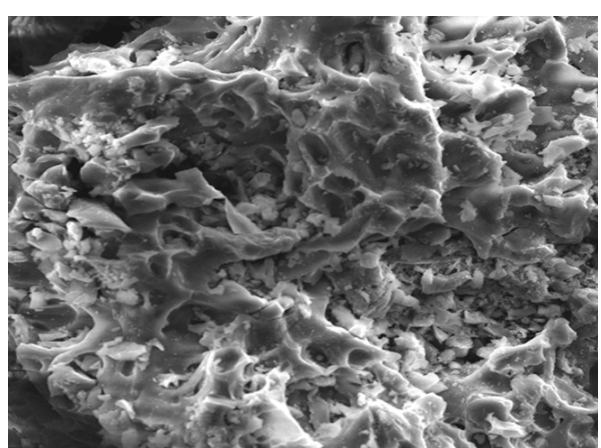

Fig. 3.4: Before Adsorption of CVD

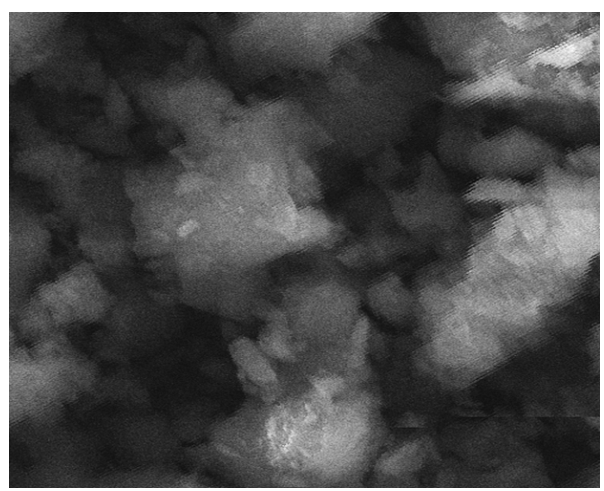

Fig. 3.5: After Adsorption of CVD

It has caves and holes type of openings on surface which might absolutely raise the surface area. After adsorption of CVD, SEM photographs are obviously shown the surfaces of CASAC are covered by CVD. This has clearly indicated that adsorbent structure was changed by adsorption of CVD. 
Fourier Transform Infrared Spectroscopic (FTIR) Studies

The CASAC spectrum of before adsorption (figure not shown) at $3412 \mathrm{~cm}^{-1}$ specified the existence of $-\mathrm{OH}$ groups of activated carbon. The aromatic $-\mathrm{CH}$ stretching group at $2920 \mathrm{~cm}^{-1}$. A peak at $2849 \mathrm{~cm}^{-1}$ specified the existence of -CO stretching group of aldehydes. The peak at $1591 \mathrm{~cm}-1$ specified the $\mathrm{N}-\mathrm{H}$ bending of primary amines and $-\mathrm{C}-\mathrm{C}$ stretching of aromatic groups. The region at $1380 \mathrm{~cm}^{-1}$ specified $-\mathrm{CH}$ stretching of alkanes group. The region at $1118 \mathrm{~cm}^{-1}$ indicated $\mathrm{C}-\mathrm{N}$ stretching of aliphatic amines. After adsorption, there is a small shift in wave number of the peaks and some of the peaks are shown in FTIR spectrum. It showed that these active groups are responsible for participation of adsorption of CVD on CASAC.

\section{Conclusion}

The Cicca acida L. stem-activated carbon (CASAC) is locally available, environmental friendly and low cost material. It was used as prospective adsorbent for removal of Crystal Violet Dye in aqueous solution. The optimum adsorbent dosage is $100 \mathrm{mg}$, optimum $\mathrm{pH}$ is 8 , and optimum contact time is 50 min used for removal of CVD. The Freundlich, Langmuir and
Tempkin adsorption isotherm models described the adsorption behaviour of CVD on CASAC. The pseudo-second order kinetic model more fit related to pseudo-first order kinetic model. The percentage removal of CVD was raised with increase in the temperature from 30 to $50^{\circ} \mathrm{C}$. The adsorption of CVD was confirmed by using before and after SEM studies. The future perspectives and challenges are to be done the recovery of spent activated carbon and adsorbate.

\section{Acknowledgment}

The authors would like to thank Bharathidasan University for giving permission to do the Ph.D. research work. The Department of Chemistry, Arignar Anna Government Arts College, Musiri, is highly appreciated for allowed the research laboratory work.

\section{Funding}

The author(s) received no financial support for the research, authorship and publication of this article.

\section{Conflict of Interest}

The authors do not have any conflict of interest.

\section{References}

1. Aljerf $L$. Biodiversity is key for more variety for better society. Biodivers. Int. J, 2017; 1(1), 4-7. https://doi.org/10.3390/ecsoc-14-00371

2. Vandevivere PC, Bianchi R, Verstreate W. Treatment and Reuse of Wastewater from the Textile Wet Processing Industry: Review of Emerging Technologies. J. Chem. Technol. Biotechnol. 1998; 72: 289-302. doi:10.1002/ (SICI)1097-4660(199808)72

3. Isik M, Sponza DT. A Batch Study for Assessing the Inhibition Effects of Direct Yellow in a Mixed Methanogenic Culture, Process Biochem. 2005; 40 (3-4): 1053-1062. doi:10.1016/j. procbio.2004.03.011

4. Alzaydien AS. Adsorption of Methylene Blue from Aqueous Solution on a Low-cost Natural Jordanian Tripoli. Am. J. Environ. Sci. 2009; 5 (1): 197-208. http://www.scipub.org/fulltext/ajes/ ajes53197-208.pdf

5. Walker GM, Weatherly LR. Fixed Bed Adsorption of Acid Dyes onto Activated Carbon. Environ.
Pollut.1998; 99 (1): 133-136. doi:10.1016/ S0269-7491(97)00166-8

6. Chem Jia-Ming, Wu Chia-Yuan. Desorption of Dye from Activated Carbon Beds: Effects of Temperature, $\mathrm{pH}$ and Alcohol. Water Res. 2001; 35 (17): 4159-4165. doi:10.1016/S00431354(01)00127-0

7. Kumar KV. Optimum Sorption Isotherm by from Contaminated Linear and Non-linear Methods for Malachite Green onto Lemon Peel. Dyes Pigm. 2007; 74 (3): 595-597. doi:10.1016/j. dyepig.2006.03.026

8. Ajay Meena, Chitra Rajagopal. Comparative Studies on Adsorptive Removal of Chromium Water Using Different Adsorbents. Indian J. Chem. Technol. 2003; 10 (1): 72-78. http://hdl. handle.net/123456789/22703

9. Aline Sartório Raymundo, Romina Zanarotto, Marciela Belisário, Madson de Godoi Pereira, Joselito Nardy Ribeiro and Araceli Verónica Flores Nardy Ribeiro. Evaluation of 
sugar-cane bagasse as bioadsorbent in the textile wastewater treatment contaminated with carcinogenic congo red dye. Braz. Arch. of Biol. Technol. 2010; 53(4), 931-938.https:// doi.org/10.15244/pjoes/26764.

10. Abu Sayid Mia MD, Uzzal Ali MD, Nur-E-Alam MD, Mafizur Rahman MD and Zahangir Alam MD 2020.Removal of Heavy Metals from Tannery Wastewater by using Sawdust and Spent Tea Leaves as an Adsorbent. Physical Science \& Biophysics Journal 2020; 4(1): 1-7. https://doi.org/10.5004/dwt.2020.26152.

11. Wei Sun, Jun-Ying Han, Qing-Jun Li and Kui Jiao. Spectrophotometric and Voltammetric Studies on the Interaction of Heparin with Crystal Violet and its Analytical Application 2007; S. Afr. J. Chem. 60, 42-46. https://doi. org/10.1016/j.jenvman.2018.07.048.

12. Pappic S, Koprivanac N, Metes A. Optimizing Polymer Induced Flocculation Process to Remove the Active Dyes from Wastewater. Environ. Technol. 2000; 21: 97-105. doi:10.1080/09593332108618143

13. Renmin Gong, Yingzhi Sun, Jian Chen, Huijun Liu, Chao Yang. Effect of chemical Mmodification on Dye Adsorption Ccapacity of peanut hull.Dyes Pigm. 2005; 67 (3): 175-181. doi:10.1016/j.dyepig.2004.12.003

14. Vadivelan V, Vasanth Kumar K. Equilibrium, Kinetics, Mechanism and Process Design for the Sorption of Methylene Blue onto Rice Husk.J. Colloid Interface Sci. 2005; 286: 90-100. doi:10.1016/j.jcis.2005.01.007

15. Perez-marin AB, Meseguer Zapata V, Ortuno JF, Aguliar M, Saez J, Liorens M. Removal of Cadmium from Aqueous Solutions by Adsorption onto Orange Waste.J. Hazard. Mater. 2007; B 139: 122-131. doi:10.1016/j. jhazmat.2006.06.008

16. Senthil Kumar P. Adsorption of Dye from Aqueous Solution by Cashewnut Shell: Studies on Equilibrium Isotherm, Kinetics and Thermodynamics of Interactions, Desalination. 2010; 261 (1): 52-60. doi:10.1016/j. desal.2010.05.032

17. Ghosh RK, Reddy DD. Tobacco Stem Ash as an Adsorbent for Removal of Methylene Blue from Aqueous Solution: Equilibrium, Kinetics, and Mechanism of Adsorption. Water Air Soil Pollut. 2013; 224 (6): 1-12. doi:10.1007/s11270013-1582-5
18. Oliveira LS, Franca AS, Alves TM, Rocha SDF. Evaluation of Untreated Coffee Husks as Potential Biosorbents for Treatment of Dye Contaminated Waters. J. Hazard. Mater. 2008; 155: 507-512. doi:10.1016/j. jhazmat.2007.11.093

19. Taty-Costodes VC, Fauduet H, Porte C, Delaccroix A. Removal of $\mathrm{Cd}(\mathrm{II})$ andPb(II) Ions, from Aqueous Solutions by Adsorption onto Sawdust of Pinus Sylvestris. J. Hazard. Mater.2003; B105: 121-142. doi:10.1016/j. jhazmat.2003.07.009.

20. Gimba CE, Abechi ES, Uzairu A, Kagbu JA. Kinetics of Adsorption of Methylene Blue onto Activated Carbon Prepared from Palm Kernel Shell. Arch. Appl. Sci. Res. 2011; 3 (1): 154-164. http://scholarsresearchlibrary.com/archive.html

21. Vikrant Sarin, Tony Sarvinder Singh, Pant KK. Thermodynamic and Eucalyptus Bark. Bioresour. Technol. 2006; 97: 1986-1993. doi:10.1016/j.biortech.2005.10.001

22. Vaughan T, Seo CE, Marshall WE. Removal of Selected Metal Ions from Aqueous Solution using Modified Corncobs. Bioresour. Technol. 2001; 78: 133-139. doi: 10.1016/S09608524(01)00007-4.

23. Mahmut Ozacar, Ayhan Sengil I. A Kinetic Study of Metal Complex Dye Sorption On to Pine Sawdust. Process Biochem. 2005; 40: 565 - 572. doi:10.1016/j.procbio.2004.01.032

24. Senthil Kumar P. Adsorption of Basic Dye onto Raw and Surface Modified Agricultural Waste. Environ. Prog. Sustain. Energy . 2013; 33(1): 87-98. doi:10.1002/ep.11756

25. Satish Manocha, Vanraj, Chauhan B, Manocha LM, Porosity Development on Activation of Char from Dry and Wet Babbool Wood, Carbon. 2002; 3(3): 133-141. doi.: http://dx.doi.org/

26. Ashok Kumar Popuri, Prashanti Guttikonda. Treatment of Textile Dyeing Industry Effluent Using Activated Carbon Prepared from Agriculture Waste (sawdust). Res. J.Pharm., Biol. Chem., 2015; 6(4): 1165-1175. http:// rjpbcs.com/pdf/2015_6(4)/[165].pdf

27. Veksha A, Sasaoka E, Azhar Uddin MD. The Influence of Porosity and Surface Oxygen Groups of Peat-based Activated Carbons on Benzene Adsorption from Dry andHumid Air. Carbon, 2009;47: 2371-2378. doi:10.1016/j.carbon.2009.04.028

28. Hameed BH, Mahmoud DK, Ahmad AL. 
Equilibrium Modelling and Kinetics Studies on the Adsorption of Basic Dye by a Lowcost Adsorbent: Coconut (Cocosnucifera) BunchWaste. J. Hazard. Mater. 2008; 158: 6572. doi:10.1016/j.jhazmat.2008.01.034

29. Langmuir, I, the Constitution and Fundamental Properties of Solids and Liquids. Part I. J. Am. Chem. Soc. 1916; 38 (2): 2221- 2295. doi: 10.1021/ja02268a002
30. Treybal RE. Mass-Transfer Operation, McGrawHill, New York, NY, USA, $3^{\text {rd }}$ Edition(1981).

31. Horsfall JNR, Michael, Spiff and Ayebaemi I. Effects of temperature on the sorption of $\mathrm{Pb}^{2+}$ and $\mathrm{Cd}^{2+}$ from aqueous solution by Caladium bicolor (Wild Cocoyam) biomass. 2005; Electron. J. Biotechnol. 8(2), 162-169. https://doi.org/10.1 080/19443994.2015.1033474. 